OPEN ACCESS

Edited by:

Xiaoming $\mathrm{Hu}$,

Sun Yat-Sen University, China

Reviewed by:

Yuxiang Zhu,

China Meteorological Administration,

China

Tuantuan Zhang,

Sun Yat-Sen University, China

*Correspondence:

Sulan Nan

nans/@cma.gov.cn

Specialty section: This article was submitted to

Atmospheric Science,

a section of the journal

Frontiers in Earth Science

Received: 12 May 2021 Accepted: 02 June 2021

Published: 14 June 2021

Citation:

Chen D, Nan S, Liu G, Zhou C, Shi R, Ao $Y$ and $L i X$ (2021) Improvement in the Prediction of Summer Precipitation

in the North China-Hetao Region Using the Tropospheric Temperature

Over the Tibetan Plateau in Spring.

Front. Earth Sci. 9:708567.

doi: 10.3389/feart.2021.708567

\section{Improvement in the Prediction of Summer Precipitation in the North China-Hetao Region Using the Tropospheric Temperature Over the Tibetan Plateau in Spring}

\author{
Dan Chen ${ }^{1,2}$, Sulan Nan ${ }^{3 *}$, Ge Liu ${ }^{3}$, Changyan Zhou ${ }^{1}$, Renrui Shi ${ }^{1}$, Yinhuan $\mathrm{Ao}^{2}$ and Xiang $\mathrm{Li}^{4}$ \\ ${ }^{1}$ Institute of Plateau Meteorology, China Meteorological Administration/Heavy Rain and Drought-Flood Disasters in Plateau and \\ Basin Key Laboratory of Sichuan Province, Chengdu, China, ${ }^{2}$ Key Laboratory for Land Surface Process and Climate Change in \\ Cold and Arid Regions, Chinese Academy of Sciences, Lanzhou, China, ${ }^{3}$ State Key Laboratory of Severe Weather, Chinese \\ Academy of Meteorological Sciences, Beijing, China, ${ }^{4}$ Sichuan Meteorological Observation and Data Center, Chengdu, China
}

We investigated the relationship between the spring tropospheric temperature over the Tibetan Plateau (TPT) and summer precipitation in eastern China on an interannual timescale using the monthly mean ERA-Interim reanalysis dataset, the HadISST dataset and the daily mean precipitation dataset for China. We found that there is a significant positive correlation between the spring TPT and summer precipitation in the North China-Hetao region. The relationship is manifested in the context of the East Asia-Pacific pattern teleconnection. In the high spring TPT index years, the geopotential height anomalies over East Asia and the western North Pacific present a negative phase of the East Asia-Pacific pattern teleconnection in the subsequent summer. This circulation pattern is beneficial for the water vapor transport from the western Pacific to inland, which further transport to the North China-Hetao region from the Yangtze River-Yellow rivers region. Anomalous upward motion occurs in the North China-Hetao region, which increases precipitation. The East Asian subtropical westerly jet shifts further north and the South Asian high weakens and shrinks westward. These conditions all favor an increase in precipitation over the North China-Hetao region. The spring TPT plays an important part in the prediction of summer precipitation in the North China-Hetao region. The improvement in the use of the spring TPT to predict summer precipitation in the North China-Hetao region is examined by comparing the prediction equations with and without the prediction factor of the spring TPT on the basis of the sea surface temperatures in key regions. After considering the impact of the spring TPT, the explanatory variance of the prediction equation for precipitation in the North China-Hetao region increases by $17.3 \%$.

Keywords: Thermal condition of the Tibetan Plateau, Precipitation in the North China-Hetao region, East AsiaPacific pattern teleconnection, Climate prediction, EAST Asian subtropical westerly jet, South Asian high 


\section{INTRODUCTION}

The Tibetan Plateau is located in the mid-to low latitudes of the Eurasian continent and is the highest plateau in the world. The thermal and dynamic effects of the Tibetan Plateau have an important impact on the Asian monsoon and precipitation in this region (Yanai et al., 1992; Wu et al., 2007; Liu et al., 2012; Wang et al., 2014; Jiang and Ting, 2017). The surface sensible heat over the Tibetan Plateau in spring is closely related to the timing of the onset of the Indian summer monsoon, with a strong (weak) surface sensible heat favoring an earlier (later) onset of the monsoon (Zhang et al., 2015). Duan et al. (2005) showed that the sensible heat over the Tibetan Plateau can be a predictor of precipitation in the valley between the Yangtze and Huaihe rivers. Weakening of the sensible heat flux over the Tibetan Plateau in spring can lead to an increase in summer precipitation in South China and a decrease in precipitation in northern and northeastern China (Duan et al., 2013). Zhao and Chen (2001) showed that the heat source over the Tibetan Plateau in spring is indicative of summer precipitation in eastern China. Latent heating over the Tibetan Plateau has an essential role in enhancing the East Asia summer monsoon circulation, intensifying the monsoon in East Asia and leading to drier conditions in central Asia (He et al., 2019). Early winter and spring snow anomalies on the Tibetan Plateau have a significant impact on the distribution of summer precipitation in China (Chen and Wu, 2000; Wang et al., 2017).

Changes in the global sea surface temperature (SST) also have an important impact on precipitation and the atmospheric circulation in eastern China. Convective activities tend to be weaker around South China Sea and the Philippines in the developing stage of El Niño. Meanwhile, the SST in the western tropical Pacific tends to be colder in summer and the western Pacific subtropical high shifts southward. As a consequence, drought conditions occur in the Indo-China peninsula and South China and there may be flooding in the area from the Yangtze River valley to the Huaihe River valley. The opposite conditions are seen in the decaying stage of El Niño (Huang and $\mathrm{Wu}, 1989$ ). Zhang et al. (2018) showed that the phase transition from La Niña to El Niño is an important precursor of prolonged spring-summer drought in northern China. El Niño can also significantly affect precipitation in China during its mature phase, with a positive precipitation anomaly occurring over the Yangtze River valley in the northern summer and a negative precipitation anomaly developing over southern and northern China (Zhang et al., 1999). Xu et al. (2019) indicated that precipitation over southern China is enhanced (suppressed) during the eastern (central) Pacific El Niño, which can be attributed to different atmospheric responses in the western North Pacific and South China Sea during the two types of ENSO (El Niño-Southern Oscillation).

The SST in the North Pacific Ocean also play an important role in drought/flood conditions in northern China. The SST anomaly over the North Pacific can intensify the western North Pacific subtropical high and increase the transport of water vapor from the tropical ocean, which favors heavy precipitation over North China (Li et al., 2017). The warm phase of the Pacific interdecadal oscillation usually corresponds to drought in northern China (Qian and Zhou, 2014).

There are strong interactions between the thermal condition of the Tibetan Plateau and the global SST. In spring and summer, the heating anomaly over the Tibetan Plateau can modulate tropical and mid-latitude air-sea interactions and affect the development of the tropical ENSO (Nan et al., 2009; Zhou et al., 2009). The SST in the tropical central and eastern Pacific in early winter and spring can also affect precipitation and the soil moisture content on the Tibetan Plateau in the same period, further modulating the local surface air temperature during the following summer (Liu et al., 2015). The tripolar SST anomaly in the North Atlantic can stimulate a stable Rossby wave train propagating downstream, which strengthens westerly winds over the Tibetan Plateau and intensifies the transfer of sensible heat from the surface of the Tibetan Plateau to the atmosphere (Cui and Wang, 2009). The thermal forcing of the Tibetan Plateau can be modulated by the SST anomaly in the North Atlantic in March and April and altered by the Indian Ocean SST anomaly in May on an interannual timescale (Zhao et al., 2018). The positive Tibetan Plateau heating anomalies can induce significant responses in the atmospheric circulation over the northern Indian Ocean, characterized by easterly anomalies in the upper troposphere as a result of the enhanced South Asian high and lower level southwesterly anomalies from the heat pump effect (Zhao et al., 2019). Hu and Duan (2015) indicated that Indian Ocean SST and thermal heating by the Tibetan Plateau are closely related in summer and are both important to the interannual variability of the East Asian monsoon. Jiang et al. (2019) pointed out that on the interannual scales, the snow depth over the eastern Tibetan Plateau is affected by ENSO, while the snow depth over the central western Tibetan Plateau is affected by Indian Ocean dipole.

These studies indicate that both the thermal condition of the Tibetan Plateau and the global SST have important indicative influences on the climate of eastern China, and there exist strong interaction between the thermal condition of the Tibetan Plateau and the global SST. However, the thermal effect of the Tibetan Plateau is seldom considered in actual forecasts for many reasons, including the reliability and timeliness of data. Previous research has shown that many variables can reflect the thermal condition of the Tibetan Plateau, such as the snow cover, the sensible and latent heat fluxes and the atmospheric heat source. However, it is also well known that there are deficiencies in the reliability of data for these variables and the quality of the data is severely affected by the local environment. The variabilities of some of these variables are inconsistent-for example, the variations in the sensible heat and the latent heat of condensation are often opposite in summer. Recent studies have introduced the tropospheric temperature over the Tibetan Plateau (TPT) to represent the thermal condition of the Tibetan Plateau, which has a good regional coherence and reflects a synthesis of various physical processes (Nan et al., 2009, Nan et al., 2019, Nan et al., 2021).

This paper focuses on the impact of the spring TPT on summer precipitation in eastern China and constructs prediction equations to study the improvement in the thermal 


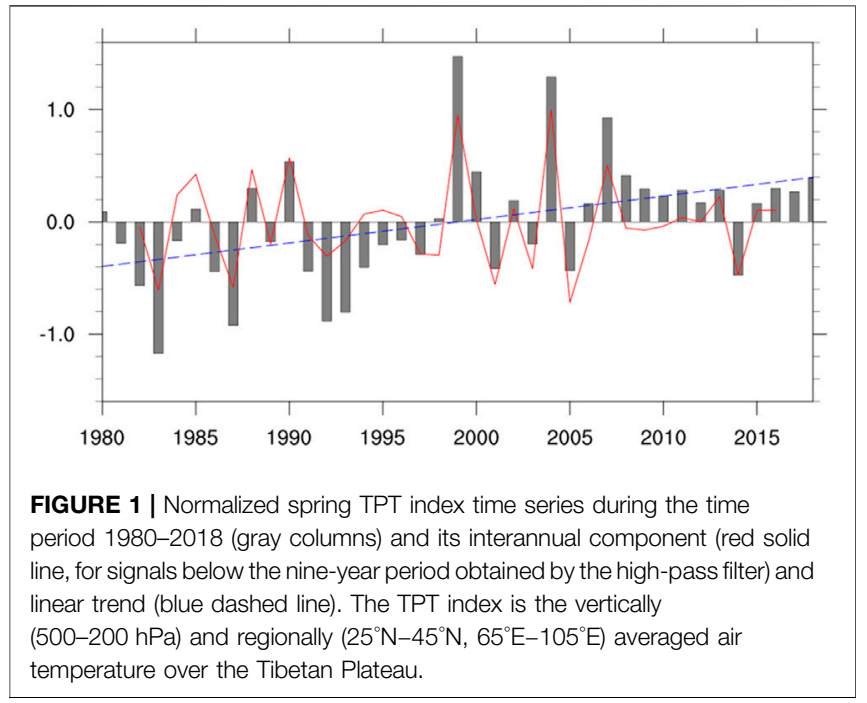

condition of the Tibetan Plateau as a predictor of summer precipitation in this region. Data and Methods describes the data and methods used in this study. Relationship Between the Spring TPT and Summer Precipitation in Eastern China presents the relationship between the spring TPT and summer precipitation in eastern China. Physical mechanism responsible for the relation between the spring TPT and summer precipitation in the North China-Hetao region further investigates the physical mechanism responsible for the relation between the spring TPT and summer precipitation in the North China-Hetao region. Prediction of Summer Precipitation in the North China-Hetao Region Using the Spring TPT shows how the spring TPT and SST can predict summer precipitation in the North China-Hetao region and Summary and Discussion presents our discussion and conclusions.

\section{DATA AND METHODS}

We used the European Centre for Medium-Range Weather Forecasts (ECMWF) ERA-Interim reanalysis dataset from 1980-2018 with a horizontal resolution of $\left(1.5^{\circ} \times 1.5^{\circ}\right)$ (Simmons et al., 2007). The variables include the geopotential height, the zonal and meridional winds, the vertical velocity, the specific humidity and the vertical integral of the water vapor flux. We also used the monthly mean SST provided by the Hadley Center with a horizontal resolution of $\left(1^{\circ} \times 1^{\circ}\right)$ (Rayner et al., $2003)$ and the daily mean precipitation data from $>2000$ stations in the latest version (V3) of surface climatological data compiled by the China National Meteorological Information Center.

We focused on the interannual scale and used the high-pass filter and signals with a period $<9$ years to represent the interannual variation signals. We used correlation analysis, partial correlation analysis and composite analysis to examine the relations among the TPT, SST and precipitation in eastern China. The prediction equations for summer precipitation in the North China-Hetao region were established by stepwise regression analysis with the SST and TPT as prediction factors. The seasons were defined according to the usual meteorological seasons (spring, March-May; summer, June-August). Student's $t$-test was used to assess the statistical significance.

\section{RELATIONSHIP BETWEEN THE SPRING TPT AND SUMMER PRECIPITATION IN EASTERN CHINA}

\section{Temporal Variation of the Spring TPT}

We selected the TPT index to represent the thermal condition of the Tibetan Plateau, which is defined as the vertically $(500-200 \mathrm{hPa})$ and regionally $\left(25-45^{\circ} \mathrm{N}, 65-105^{\circ} \mathrm{E}\right)$ averaged temperature (Nan et al., 2009, Nan et al., 2019, Nan et al., 2021). Figure 1 shows the time series of the spring TPT during the period 1980-2018. It shows a significant upward linear trend of $0.2^{\circ} \mathrm{C} /$ decade $(>99 \%$ significance level). The TPT also has a clear interannual variation accounting for $52.7 \%$ of the total variability of the covariance. This study is focused on the relation between the spring TPT and summer precipitation in eastern China on an interannual timescale and the TPT index and other variables were filtered through a ninepoint high-pass filter.

\section{Relationship Between the Spring TPT and Summer Precipitation in the North China- Hetao Region}

Figure 2 shows a correlation map of the spring TPT index with the summer 2000-station precipitation in China for the time period 1980-2018. It is characterized by a negative-positivenegative-positive pattern from north to south in eastern China. Significantly negative correlations are seen in northeast China and

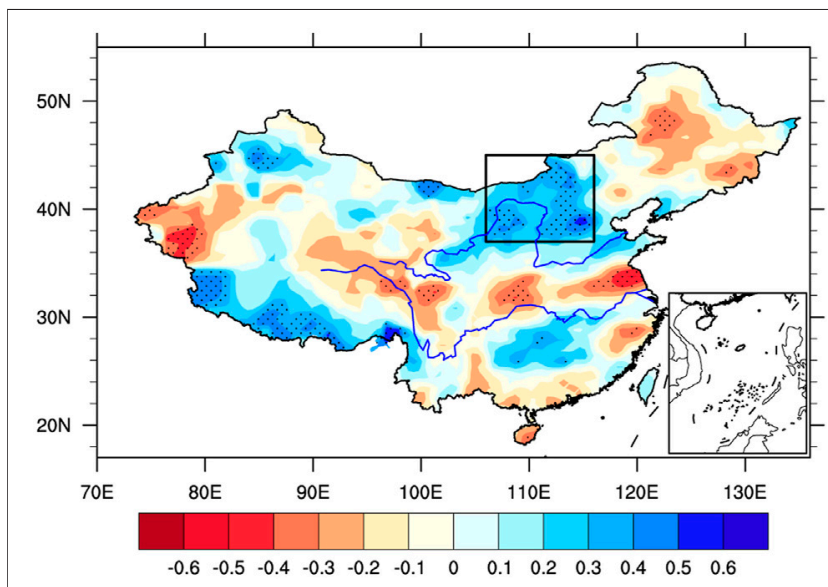

FIGURE 2 | Correlation map of the spring TPT index with the 2000-station summer precipitation in China on an interannual timescale for the time period 1980-2018. The box represents the North China-Hetao region $\left(37^{\circ} \mathrm{N}-45^{\circ} \mathrm{N}, 106^{\circ} \mathrm{E}-116^{\circ} \mathrm{E}\right)$. The stippled areas are significant at the $95 \%$ confidence level. 

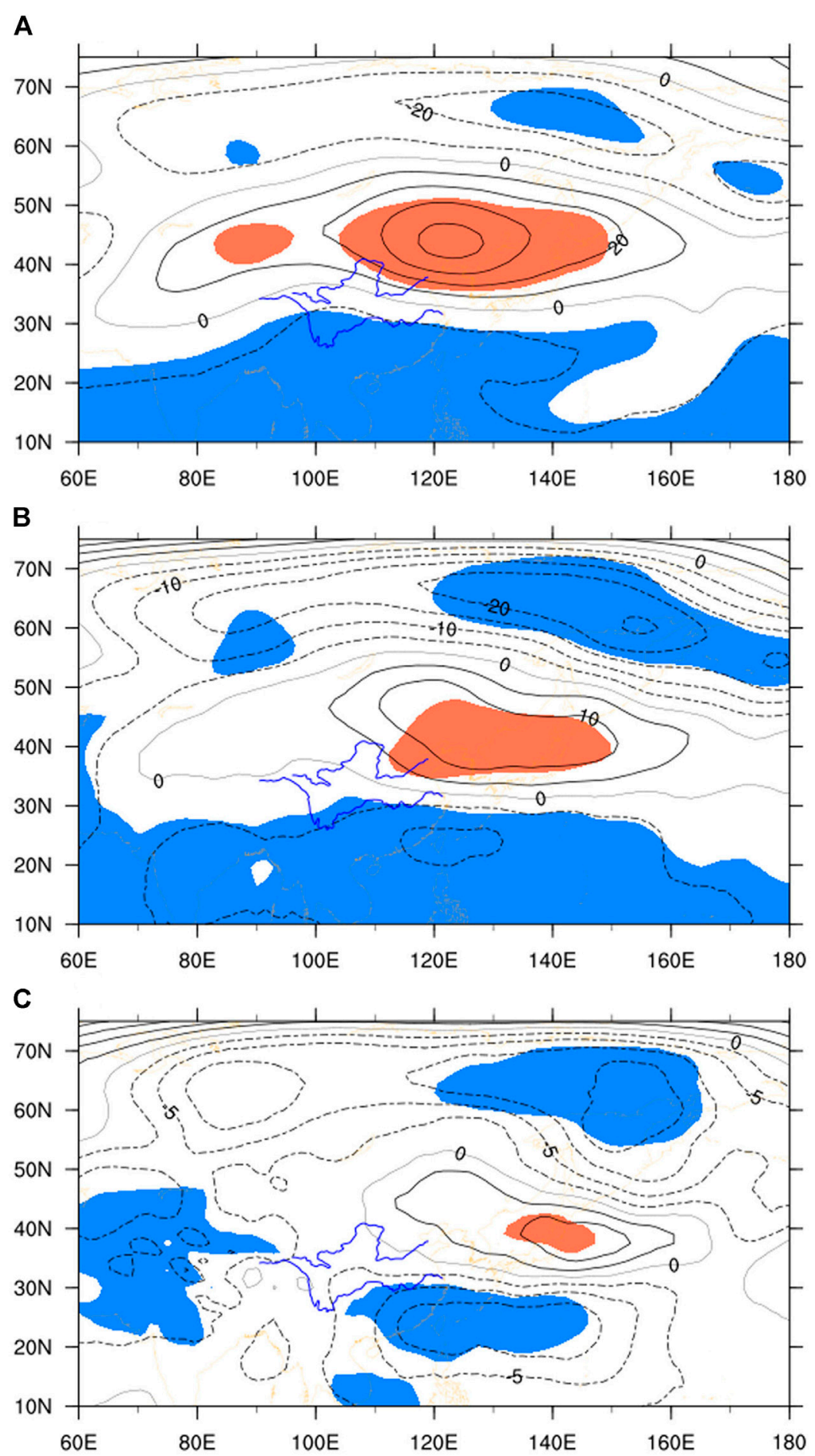

FIGURE 3 | Composite differences in (A) 200, (B) 500, and (C) 850 hPa geopotential high anomalies (m) between the high and low spring TPT index cases. The shaded areas are significant at the $90 \%$ confidence level.

the Yangtze-Huaihe river valleys. Significantly positive correlations mainly appear in the North China-Hetao region and the south of the middle reaches of the Yangtze River valley. This indicates that when the spring TPT is high, precipitation in northeast China and the Yangtze-Huaihe river valleys tends to be less than normal and precipitation in the North China-Hetao region and the south of the middle reaches of the Yangtze River valley tends to be greater than normal in the subsequent summer. The significantly positive 
correlation region in the North China-Hetao region is large-scale, which is useful and popular in actual prediction. Below, this study focuses on relationship between the spring TPT and summer precipitation in the North China-Hetao region. The summer precipitation in the North China-Hetao region (as shown in the box in Figure 2) has a correlation coefficient of 0.41 (>97\% confidence level) with the spring TPT index on an interannual timescale.

\section{PHYSICAL MECHANISM RESPONSIBLE FOR THE RELATION BETWEEN THE SPRING TPT AND SUMMER PRECIPITATION IN THE NORTH CHINA-HETAO REGION}

\section{East Asia-Pacific Pattern Teleconnection}

We examine the variations in the atmospheric circulation associated with the spring TPT by composite analysis, based on the inter-annual time series in Figure 1 (red solid line). Six high $(1985,1988,1990,1999,2004$, and 2007) and six low (1983, 1987, 2001, 2003, 2005, and 2014) spring TPT index years are selected, in which the fluctuations of the TPT index exceed one standard deviation. Figure 3 indicates the composite differences in the anomalous geopotential high between high and low spring TPT index cases in the upper, mid-and lower troposphere. There is a meridional negative-positive-negative pattern of geopotential height anomalies over East Asia and the western Pacific in the high spring TPT index years, with negative values over South China and the lower latitudes of the western North Pacific and to the north of the Okhotsk Sea and positive values at mid-latitudes over East Asia. This pattern is similar to the negative phase of the East Asia-Pacific pattern (EAP) (Huang and Li, 1987; Nitta, 1987) and shows an equivalent barotropic feature over the whole troposphere. The EAP is an important teleconnection affecting both the East Asian summer monsoon and precipitation (Chen and Zhai, 2015; Li et al., 2018; Hu et al., 2020). Its negative phase can cause a decrease in precipitation in the Yangtze-Huaihe river basin and an increase in precipitation in the Yellow river basin (Huang and Li, 1987; Huang, 1992; Wang et al., 2018). These results are in agreement with the relation between the spring TPT and summer precipitation (Figure 3), indicating that the spring TPT can affect summer precipitation in eastern China through the EAP teleconnection.

In the negative phase of the EAP, an anomalous cyclone appears around the Okhotsk Sea, which is not conducive to the southward movement of cold air from mid-to high latitudes to northern China. An anomalous anticyclone controls the mid-latitudes of East Asia. The North China-Hetao region is located on the southern and southwestern flanks of the anomalous anticyclone. An anomalous cyclone appears in South China and the lower latitudes of the western Pacific. Between the anomalous anticyclone at the mid-latitudes of East Asia and the anomalous cyclone at the lower latitudes of the western Pacific, anomalous easterly winds flow from the western North Pacific to inland East Asia and diverge from the Yangtze-Yellow river region to the North China-Hetao region and South China (Figures 4A-C). These anomalous circulations favor the transport of more water vapor from the western Pacific to the North China-Hetao region and South China, increasing of precipitation in these regions (Figure 4D).

Figure 5A shows the composite differences in the summer $500 \mathrm{hPa}$ vertical velocity between the high and low spring TPT index cases. In the high spring TPT index years, significant positive anomalies appear between the Yangtze and Yellow rivers, indicating anomalous descending motion, which is also seen in the latitude-height cross-section of the composite differences in vertical velocity along $106-116^{\circ} \mathrm{E}$ (Figure 5B). Such anomalous descending motion favors a decrease in precipitation between the Yangtze and Yellow rivers. At the same time, significant negative anomalies of vertical velocity appear throughout the troposphere over the North China-Hetao region between 36 and $45^{\circ} \mathrm{N}$, suggesting anomalous ascending motion (Figures $5 \mathbf{A}, \mathbf{B}$ ) and favoring an increase in precipitation in this region. The distribution of anomalous vertical velocity in the North China-Hetao and the Yangtze-Yellow river regions associated with the high spring TPT (Figure 5) corresponds well with the anomalous distribution of precipitation in Figure 2.

\section{East Asian Subtropical Westerly Jet and South Asian High}

In the composite differences of the $200 \mathrm{hPa}$ horizontal winds (Figure 4A), anomalous westerly winds prevail between the anomalous cyclone in northeast Asia and the anomalous anticyclone at mid-latitudes over East Asia. Figure 6A shows the composite differences in the $200 \mathrm{hPa}$ zonal wind between high and low spring TPT index cases. The region of northeast Asia from east of Lake Baikal to the Okhotsk Sea between 50 and $65^{\circ} \mathrm{N}$ and the mid-latitude region over East Asia between 30 and $40^{\circ} \mathrm{N}$ are covered by significant positive and negative anomalies, respectively. These regions are controlled in the climatology by the westerly jet. These zonal wind anomalies therefore indicate an increase in westerly winds in northeast Asia and a decrease in westerly winds at mid-latitudes in East Asia, implying a northward shift of the East Asian subtropical westerly jet.

Figure 6B shows the axes of the westerly jet in the high and low TPT index cases. The axis of the westerly jet shifts further north in the high TPT index cases than in the low TPT index cases, especially in East Asia. Previous studies have indicated that the position of the East Asian subtropical westerly jet in summer has an important impact on the East Asian summer monsoon and further influences summer precipitation in China (Yu et al., 2004; Wang and Zou, 2016; Xuan et al., 2018). When the East Asian subtropical westerly jet is abnormally north, precipitation increases abnormally in northern China and the Hetao area (Kuang and Zhang, 2006). This implies that the TPT probably links with the 

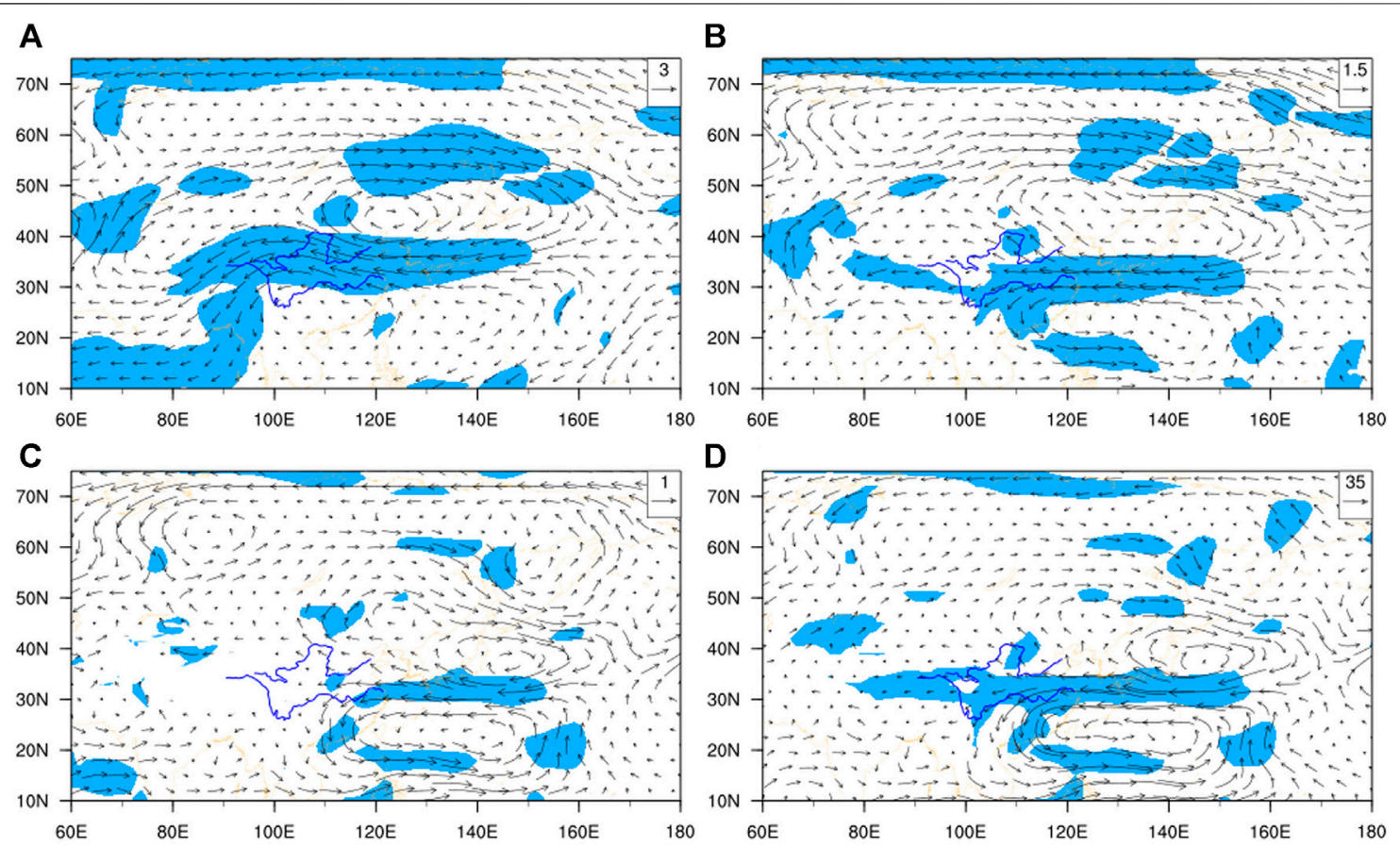

FIGURE 4 | Composite differences in (A) 200, (B) 500, and (C) $850 \mathrm{hPa}$ wind vector anomalies $\left(\mathrm{m} \mathrm{s}^{-1}\right)$ and (D) the vertical integral of water vapor transport anomalies $\left(\mathrm{kg} \mathrm{m}^{-1} \mathrm{~s}^{-1}\right)$ between the high and low spring TPT index cases. The shaded areas are significant at the 95\% confidence level.

anomaly of precipitation in the North China-Hetao region via modulating the position of the East Asian subtropical westerly jet.

In the composite difference of the $200 \mathrm{hPa}$ geopotential height between the high and low spring TPT index cases (Figure 3A), significant negative anomalies cover the lower latitudes from the western Pacific to East and South Asia, implying that the anomaly in the South Asian high corresponds to the high spring TPT. Figure 7 presents the composites for the $200 \mathrm{hPa}$ geopotential high for the high and low spring TPT index cases. In the high spring TPT index years (Figure 7A), the area of the South Asian high above $12.5 \mathrm{~km}$ is clearly smaller in summer than in the low spring TPT index years (Figure 7B). The most eastern points of the $12.5 \mathrm{~km}$ contour line are located near 120 and $135^{\circ} \mathrm{E}$ in the high and low spring TPT index cases, respectively-that is, the South Asian high weakens and shrinks westward in the high TPT index years compared with the low spring TPT index years. Previous research has indicated that the weakening and westward shrinking of the South Asian high can induce floods in northern China (Huang and Qian, 2004; Huang et al., 2006). The change in the atmospheric thermal condition over the Tibetan Plateau is therefore also probably related to the anomaly in precipitation over northern China by the change in the position of the South Asian high.

In general, when the spring TPT is high, the East Asian subtropical westerly jet moves northward and the South Asian high weakens and shrinks westward. These conditions favor an increase in precipitation in the North China-Hetao region.

\section{PREDICTION OF SUMMER PRECIPITATION IN THE NORTH CHINA- HETAO REGION USING THE SPRING TPT}

The above study shows that the spring TPT is closely related to summer precipitation in the North China-Hetao region, which makes it possible to use the spring TPT to improve the prediction of summer precipitation in the region. Previous studies have also concluded that SST anomalies are the main interannual prediction signals of summer precipitation in eastern China (Huang and $\mathrm{Wu}$, 1989; Zhu et al., 2015). Therefore, we tries to study the improvement of the thermal condition of the Tibetan Plateau for summer precipitation prediction in the North China-Hetao region, by introducing the thermal factor of the Tibetan Plateau into the prediction equation on the basis of the SST factors.

We used partial correlation analysis to determine the areas of high correlation in which the SSTs are closely related to regional precipitation in the North China-Hetao region, but independent of the TPT. The SSTs in these high-correlation areas were then used to predict the regional precipitation in summer. Based on the effect of SSTs in these high-correlation regions, we evaluated the improvement in the use of the spring TPT for the prediction of summer precipitation in the North China-Hetao region by comparing the prediction results for regional precipitation before 


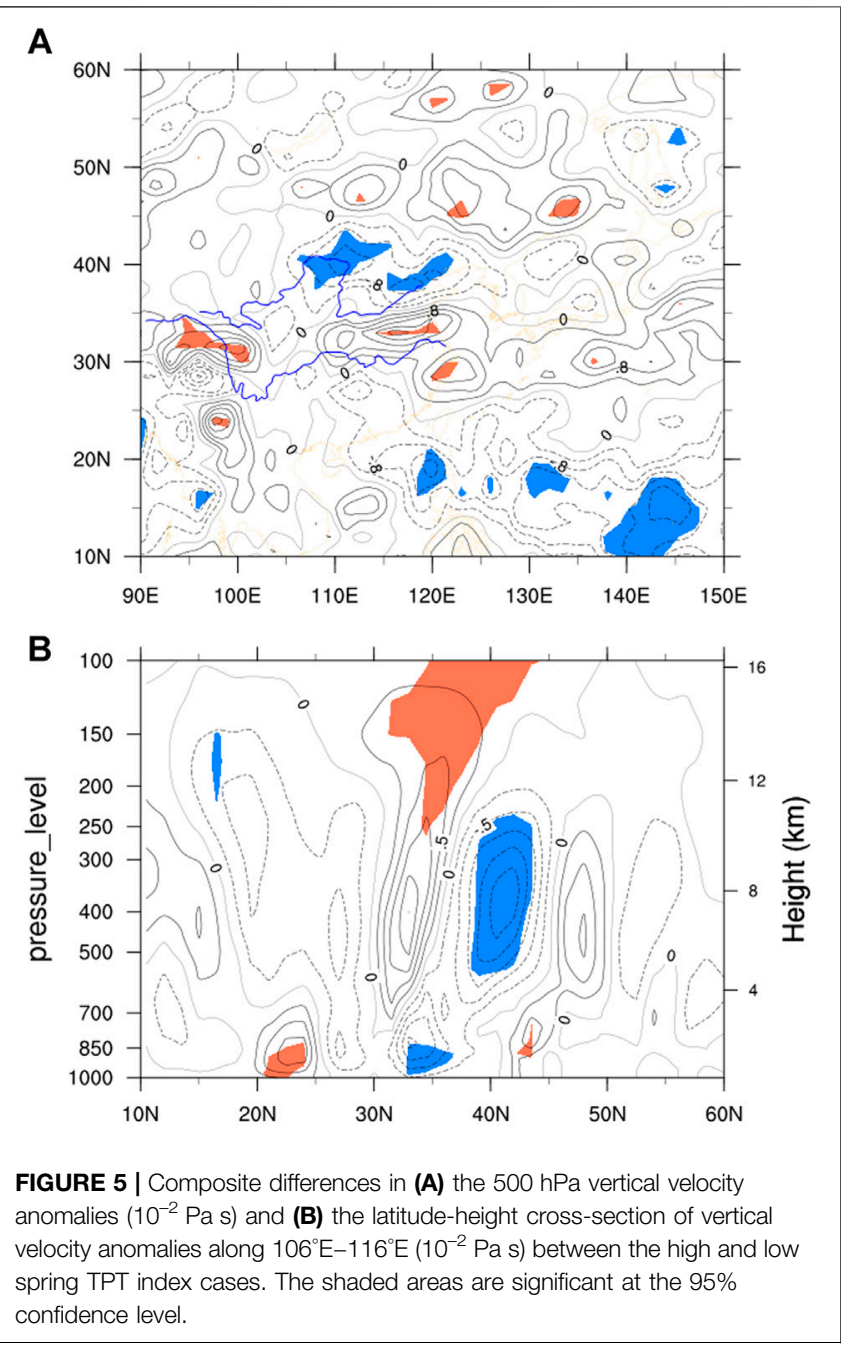

and after considering the prediction factor of the spring TPT (Figure 8; Table 1).

Figure 8A shows the partial correlation map between summer precipitation in the North China-Hetao region and the SST in the previous spring, with the effect of the spring TPT removed in each grid. Significant negative values covering a large area appear at midto high latitudes over the North Pacific (MHNP) and the tropical central Pacific (TCP) and positive values are seen in the tropical eastern Pacific (TEP) and the eastern Indian Ocean (EIO). The standardized and regionally averaged SSTs in these regions are used as the basic prediction factors. There are also other significant areas of correlation over the oceans, but these areas are small and therefore the SSTs in these regions were not selected as prediction factors.

We constructed prediction Eq. 1 for summer precipitation in the North China-Hetao region using stepwise regression. The SST in the tropical eastern Pacific was eliminated and only the SSTs in the MHNP, TCP and EIO were selected as significant prediction factors for summer precipitation in the North China-Hetao region. The correlation coefficient between the regressed and observed summer precipitation time series in the North China-Hetao region (Figure 8B) is 0.52, above the $99 \%$ confidence level (Table 1). The explanatory variance of prediction factors for precipitation in the North China-Hetao region is $26.6 \%$.

After introducing the spring TPT factor, we obtained prediction Eq. 2 for summer precipitation in the North China-Hetao region. The SSTs in the TCP and EIO are still significant prediction factors and the SST in the MHNP is eliminated. The correlation coefficient between the regressed and observed precipitation time series increases to 0.66 , exceeding the $99 \%$ confidence level (Table 1). The explanatory variance of the spring TPT and SSTs in the TCP and EIO for summer precipitation in the North China-Hetao region reaches $43.9 \%$, which is $17.3 \%$ more than that of the SSTs in the MHNP, TCP and EIO for the precipitation in this region.

Figure 8B shows the variations in the observed and fitted summer precipitation in the North China-Hetao region. The fitting value, using both spring TPT and SSTs in the TCP and EIO as prediction factors, is closer to the observed precipitation than the fitting value considering only the effect of SSTs.

Stepwise regression fitting equation:

$$
\begin{aligned}
& \mathrm{P}_{\mathrm{NH}}=-0.13-6.4 \mathrm{SST}_{\mathrm{MHNP}}-12.2 \mathrm{SST}_{\mathrm{TCP}}+13.7 \mathrm{SST}_{\mathrm{EIO}} \\
& \mathrm{P}_{\mathrm{NH}}=-0.08-16.9 \mathrm{SST}_{\mathrm{TCP}}+16.4 S S \mathrm{~T}_{\mathrm{EIO}}+11.2 \mathrm{TPT}
\end{aligned}
$$

Where $\mathrm{P}_{\mathrm{NH}}$ is the summer precipitation in the North China-Hetao region, $\mathrm{SST}_{\mathrm{MHNP}}$ is the SST of the MHNP in spring, $\mathrm{SST}_{\mathrm{TCP}}$ is the SST of the TCP in spring, $\mathrm{SST}_{\mathrm{EIO}}$ is the SST of the EIO and TPT is the tropospheric temperature over the Tibetan Plateau in spring.

The spring TPT therefore plays an important part in the prediction of summer precipitation in the North China-Hetao

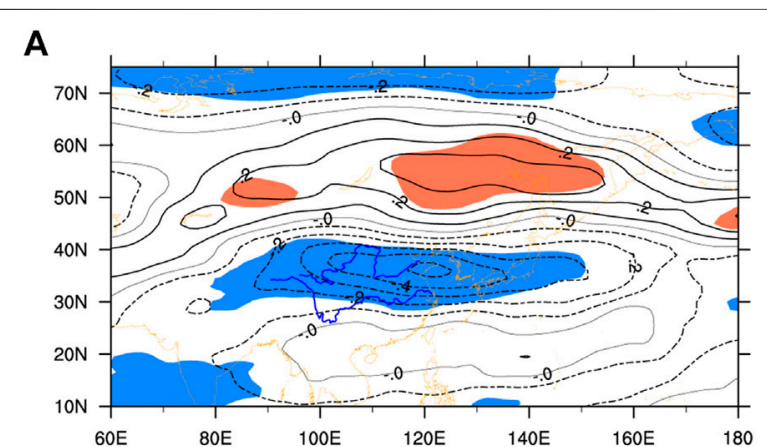

B

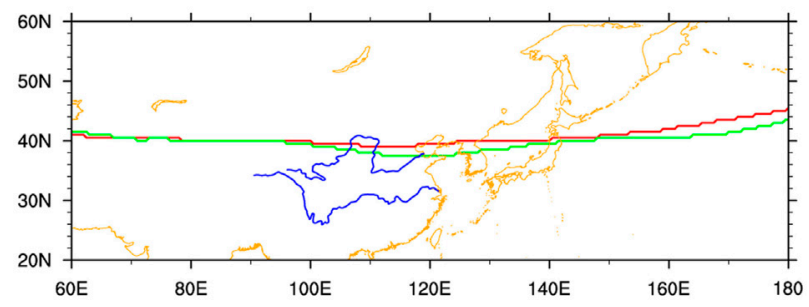

FIGURE 6 | (A) Composite differences in the $200 \mathrm{hPa}$ zonal wind anomalies $\left(\mathrm{m} \mathrm{s}^{-1}\right)$ between the high and low spring TPT index cases. (B) Axes of the westerly jet in the high (red) and low (green) TPT index cases. The shaded areas in part (A) are significant at the $95 \%$ confidence level. 

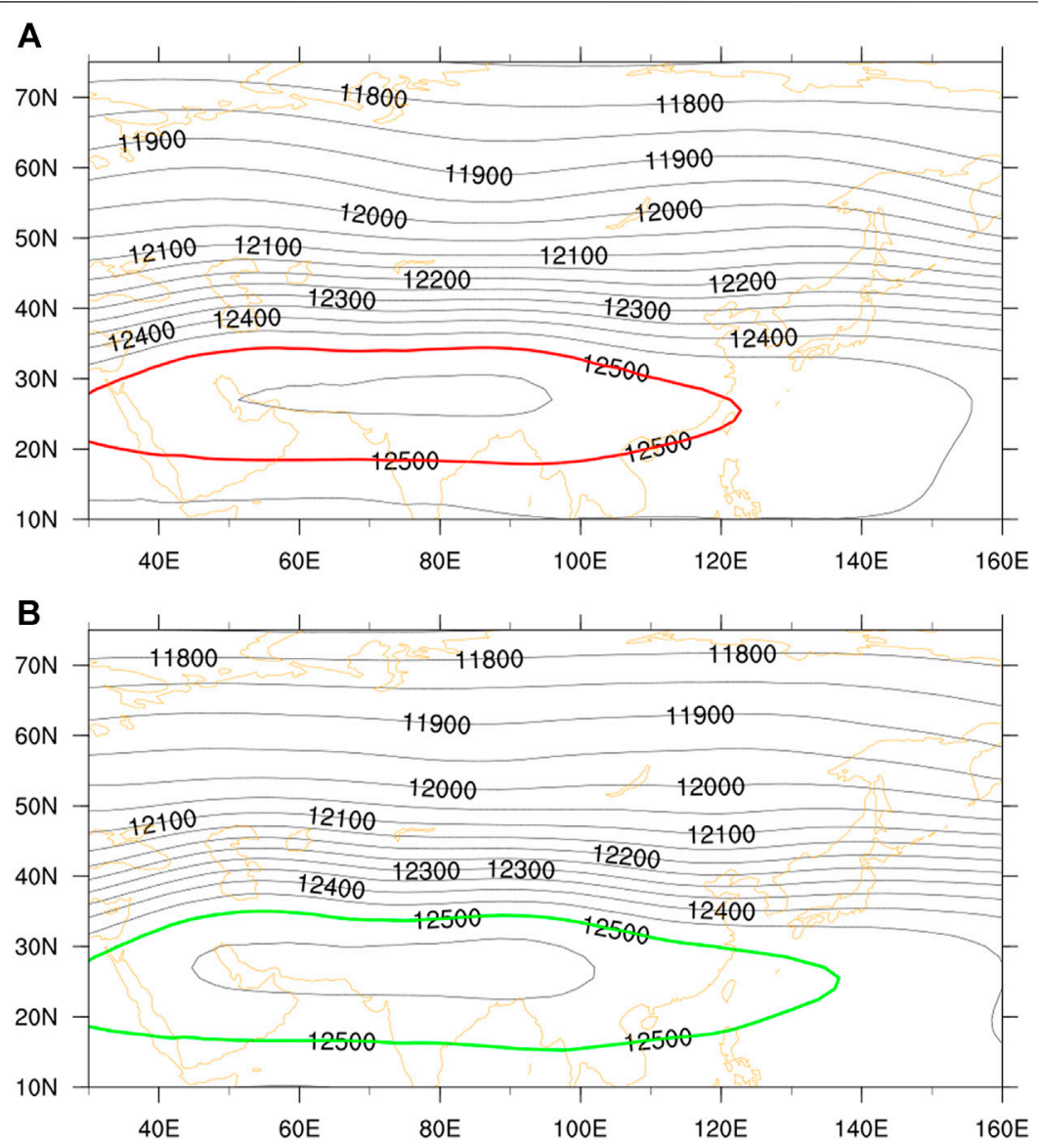

FIGURE 7 | Composite in the $200 \mathrm{hPa}$ geopotential high (m) for the (A) high and (B) low spring TPT index cases.

region. After introducing the effect of the TPT on the basis of the SST, the prediction skill for summer precipitation in this region increased by $17.3 \%$. Therefore the role of the spring TPT should not be ignored in short-term predictions of summer precipitation in the North China-Hetao region.

\section{SUMMARY AND DISCUSSION}

Using the monthly mean ERA-Interim reanalysis dataset, the HadISST dataset and the daily mean precipitation dataset for the time period 1980-2018, we investigated the relationship between the springtime TPT and summer precipitation over eastern China on an interannual timescale. There was a significant correlation of negative-positive-negative-positive from northeast China to South China between the spring TPT and precipitation in eastern China, with significant positive correlation in the North China-Hetao region and South China and negative correlation in northeast China and the Yangtze-Yellow river region. This indicates that, associated with a high (low) spring TPT, precipitation in the North China-Hetao region and South China tends to be more (less) than normal, whereas the precipitation in northeast China and the Yangtze-Yellow river region tends to be less (more) than normal in the subsequent summer. Precipitation in the North China-Hetao region has a correlation coefficient of 0.41 with the spring TPT index, exceeding the $97 \%$ confidence level.

The relationship between the spring TPT and precipitation in the North China-Hetao region was considered in the context of the EAP teleconnection. In the high spring TPT index years, the geopotential height anomalies in East Asia and the western North Pacific present a negative phase of the EAP teleconnection in the subsequent summer, characterized by negative anomalies over South China and the lower latitudes of the western Pacific and the mid-to high latitudes north of the Okhotsk Sea and by positive anomalies in the mid-latitudes of East Asia. Under this background, anomalous easterly winds prevail between the anomalous anticyclone at mid-latitudes in East Asia and the western Pacific and the anomalous cyclone in South China and the lower latitudes of the western Pacific, which brings more water vapor inland from the western Pacific and a divergence from the Yangtze-Yellow river region to the North China-Hetao region. Anomalous upward (downward) motion occurs in the North China-Hetao (Yangtze-Yellow river) region, favoring an increase (decrease) in precipitation in the North China-Hetao (Yangtze-Yellow river) region. Under the background of the negative phase of the EAP teleconnection, anomalous westerly 

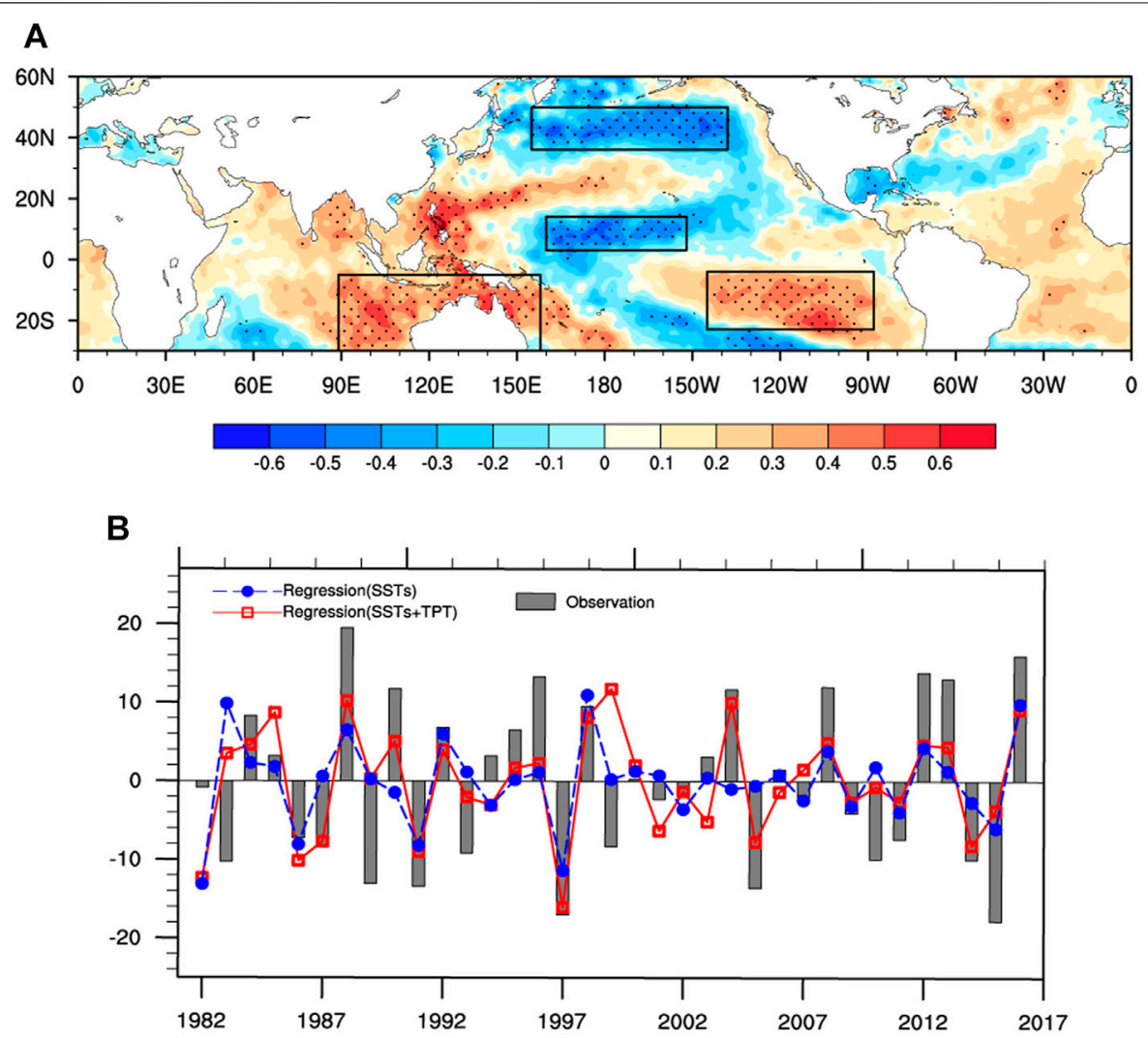

FIGURE 8 | (A) Partial correlation coefficient between summer precipitation in the North China-Hetao region and the preceding spring SST after removal of the impact of the spring TPT. (B) Times series of the observed and regressed anomalous summer precipitation over the North China-Hetao region ( $\mathrm{mm}$ ). The shaded areas in part (A) are significant at the $95 \%$ confidence level.

TABLE 1 | Stepwise regression of summer precipitation in the North China-Hetao region.

\begin{tabular}{cccccc}
\hline SST in MHNP & SST in TCP & SST in TEP & SST in EIO & $\begin{array}{c}\text { TPT } \\
\text { (observed, } \\
\text { fitted) }\end{array}$ \\
\hline 1 & -6.4 & -12.2 & $/$ & 13.7 & - \\
2 & $/$ & -16.9 & $/$ & 16.4 & $0.52^{\star \star}$ \\
\hline
\end{tabular}

Note: the prediction factors are the previous spring SSTS and TPT. The range of each sea area is shown in Figure 8a. - represent the prediction factor which has not being introduced. / represent the prediction factor which has being eliminated by stepwise regression. ${ }^{* *}$ Above the $99 \%$ confidence level.

winds prevail between the anomalous cyclone over the Okhotsk Sea and the anomalous anticyclone at mid-latitudes in East Asia and the western Pacific in the subsequent summer, indicating a northward shift in the East Asian subtropical westerly jet. The South Asia high weakens and shrinks westward. These conditions all favor an increase in precipitation in the North China-Hetao region.

The improvement in the use of the spring TPT to predict summer precipitation in the North China-Hetao region was examined by comparing the prediction equations without and with the prediction factor of the spring TPT on the basis of the SSTs, which have high correlations with precipitation in the North China-Hetao region. We first established a prediction equation for precipitation in the North China-Hetao region based on the prediction factor of SSTs in the MHNP, TCP, and
EIO. The correlation coefficient between the regressed and observed summer precipitation time series is 0.52 . The spring TPT was then introduced as a prediction factor for precipitation in the North China-Hetao region. Another prediction equation was then established based on the prediction factors of the spring TPT and SSTs in the TCP and EIO. The correlation coefficient between the predicted and observed precipitation was improved to 0.66. After considering the impact of the spring TPT, the explanatory variance of the prediction equation for precipitation in the North China-Hetao region increased by $17.3 \%$.

This study focused on the impact and prediction of the spring TPT for precipitation in the subsequent summer in eastern China on interannual scales. The actual forecasts cover various 
timescales. It is worth investigating further how to apply this interannual link to the prediction of actual precipitation.

This study examined the improvement in the prediction of summer precipitation in the North China-Hetao region using the spring TPT on the basis of the SSTs. Previous research has shown that many variables can affect the precipitation of North China-Hetao region, such as the snow cover (Yang and $\mathrm{Xu}$, 1994) and the sea ice concentration (Li and Zeng, 2008). The multiple factors should be explored in the future to improve the prediction skill for the precipitation in the North China-Hetao region.

\section{DATA AVAILABILITY STATEMENT}

Publicly available datasets were analyzed in this study. This data can be found here: https://apps.ecmwf.int/datasets/, https://www. metoffice.gov.uk/hadobs/.

\section{REFERENCES}

Chen, L., and Wu, R. (2000). Interannual and Decadal Variations of Snow Cover over Qinghai-Xizang Plateau and Their Relationships to Summer Monsoon Rainfall in China. Adv. Atmos. Sci. 17, 18-30. doi:10.1007/s00376-000-0040-7

Chen, Y., and Zhai, P. (2015). Synoptic-scale Precursors of the East Asia/Pacific Teleconnection Pattern Responsible for Persistent Extreme Precipitation in the Yangtze River Valley. Q.J.R. Meteorol. Soc. 141, 1389-1403. doi:10.1002/qj.2448

Cui, Y., and Wang, C. (2009). Comparison of Sensible and Latent Heat Fluxes during the Transition Season over the Western Tibetan Plateau from Reanalysis Datasets. Prog. Nat. Sci. 19 (6), 719-726. doi:10.1016/j.pnsc.2008.11.001

Duan, A., Liu, Y., and Wu, G. (2005). Heating Status of the Tibetan Plateau from April to June and Rainfall and Atmospheric Circulation Anomaly over East Asia in Midsummer. Sci. China Ser. D-earth Sci. 48 (2), 250-257. doi:10.1360/ 02yd0510

Duan, A., Wang, M., Lei, Y., and Cui, Y. (2013). Trends in Summer Rainfall over China Associated with the Tibetan Plateau Sensible Heat Source during 19802008. J. Clim. 26 (1), 261-275. doi:10.1175/JCLI-D-11-00669.1

He, C., Wang, Z., Zhou, T., and Li, T. (2019). Enhanced Latent Heating over the Tibetan Plateau as a Key to the Enhanced East Asian Summer Monsoon Circulation under a Warming Climate. J. Clim. 32 (11), 3373-3388. doi:10. 1175/JCLI-D-18-0427.1

Hu, J., and Duan, A. (2015). Relative Contributions of the Tibetan Plateau thermal Forcing and the Indian Ocean Sea Surface Temperature basin Mode to the Interannual Variability of the East Asian Summer Monsoon. Clim. Dyn. 45, 2697-2711. doi:10.1007/s00382-015-2503-7

Hu, P., Feng, G., Dogar, M. M., Cheng, J., and Gong, Z. (2020). Joint Effect of East Asia-Pacific and Eurasian Teleconnections on the Summer Precipitation in North Asia. J. Meteorol. Res. 34 (3), 559-574. doi:10.1007/s13351-020-9112-z

Huang, R. H. (1992). The East Asia/Pacific Pattern Teleconnection of Summer Circulation and Climate Anomaly in East Asia. J. Meteorol. Res 6, 25-37.

Huang, R. H., and Li, W. J. (1987). Influence of the Heat Source Anomaly over the Western Tropical Pacific on the Subtropical High over East Asia (in Chinese). Proc. Int. Conf. on the General Circulation of East Asia. April 10-15, 1987, Chengdu, China. 40-45. Available at: https://www.ixueshu.com/document/ 946e317b94c48768256dff31f1b37dc5318947a18e7f9386.html

Huang, R., and Wu, Y. (1989). The Influence of ENSO on the Summer Climate Change in China and its Mechanism. Adv. Atmos. Sci. 6, 21-31. doi:10.1007/ BF02656915

Huang, Y., and Qian, Y. (2004). Relationship between South Asian High and Characteristic of Precipitation in Mid-and Lower-Reaches of Yangtze River and

\section{AUTHOR CONTRIBUTIONS}

DC: Methodology, Data curation, Writing-Original draft preparation; SN: Conceptualization, Writing-Reviewing and Editing; CZ: Writing-Reviewing and Editing; RS: Investigation; GL: Writing-Reviewing and Editing; YA: Writing-Reviewing and Editing; XL: Data collection.

\section{FUNDING}

This work was jointly sponsored by the National Natural Science Foundation of China (41775084); Opening Found of Key Laboratory of Land Surface Process and Climate Change in Cold and Arid Regions, Chinese Academy of Sciences (LPCC2019007); Key Special Projects of National Key R and D Program of China (2018YFC1505706); National Natural Science Foundation of China (42075045) and the Basic Research Fund of Chinese Academy of Meteorological Sciences (2019Z008; 2021Z007).

North China (In Chinese). Plateau Meteorol. 23 (1), 68-74. doi:10.3321/j.issn: 1000-0534.2004.01.010

Huang, Y., Qian, Y., and Wan, Q. (2006). Simulation and Analysis about the Effects of Geopotential Height Anomaly in Tropical and Subtropical Region on Droughts or Floods in the Yangtze River Valley and North China. J. Meteor Res. 20 (4), 426-436. doi:10.1016/S1872-2032(06)60022-X

Jiang, X., and Ting, M. (2017). A Dipole Pattern of Summertime Rainfall across the Indian Subcontinent and the Tibetan Plateau. J. Clim. 30, 9607-9620. doi:10. 1175/JCLI-D-16-0914.1

Jiang, X., Zhang, T., Tam, C. Y., Chen, J., Lau, N. C., Yang, S., et al. (2019). Impacts of ENSO and IOD on Snow Depth over the Tibetan Plateau: Roles of Convections over the Western North Pacific and Indian Ocean. J. Geophys. Res. Atmos. 124, 11961-11975. doi:10.1029/2019JD031384

Kuang, X., and Zhang, Y. (2006). Impact of the Position Abnormalities of East Asian Subtropical Westerly Jet on Summer Precipitation in Middle-Lower Reaches of Yangtze River (In Chinese). Plateau Meteor, 25 (3), 266-277. doi:10. 3321/j.issn:1000-0534.2006.03.004

Li, F., and Zeng, Q. (2008). Statistical Prediction of East Asian Summer Monsoon Rainfall Based on SST and Sea Ice Concentration. J. Meteorol. Soc. Jpn. 86 (1), 237-243. doi:10.2151/jmsj.86.237

Li, H.-X., Chen, H.-P., and Wang, H.-J. (2017). Influence of North Pacific SST on Heavy Precipitation Events in Autumn over North China. Atmos. Oceanic Sci. Lett. 10 (1), 21-28. doi:10.1080/16742834.2017.1237256

Li, H., Zhai, P., Chen, Y., and Lu, E. (2018). Potential Influence of the East AsiaPacific Teleconnection Pattern on Persistent Precipitation in South China: Implications of Atypical Yangtze River Valley Cases. Weather Forecast. 33 (1), 267-282. doi:10.1175/WAF-D-17-0011.1

Liu, G., Zhao, P., Chen, J., and Yang, S. (2015). Preceding Factors of Summer Asian-Pacific Oscillation and the Physical Mechanism for Their Potential Influences. J. Clim. 28 (7), 2531-2543. doi:10.1175/ JCLI-D-14-00327.1

Liu, Y., Wu, G., Hong, J., Dong, B., Duan, A., Bao, Q., et al. (2012). Revisiting Asian Monsoon Formation and Change Associated with Tibetan Plateau Forcing: II. Change. Clim. Dyn. 39 (5), 1183-1195. doi:10.1007/s00382-012-1335-y

Nan, S., Zhao, P., Chen, J., and Liu, G. (2021). Links between the thermal Condition of the Tibetan Plateau in Summer and Atmospheric Circulation and Climate Anomalies over the Eurasian Continent. Atmos. Res. 247, 105212. doi:10.1016/j. atmosres.2020.105212

Nan, S., Zhao, P., and Chen, J. (2019). Variability of Summertime Tibetan Tropospheric Temperature and Associated Precipitation Anomalies over the Central-Eastern Sahel. Clim. Dyn. 52 (3-4), 1819-1835. doi:10.1007/s00382018-4246-8 
Nan, S., Zhao, P., Yang, S., and Chen, J. (2009). Springtime Tropospheric Temperature over the Tibetan Plateau and Evolutions of the Tropical Pacific SST. J. Geophys. Res. 114 (D10). doi:10.1029/2008JD011559

Nitta, T. (1987). Convective Activities in the Tropical Western Pacific and Their Impact on the Northern Hemisphere Summer Circulation. J. Meteorol. Soc. Jpn. 65, 373-390. doi:10.2151/jmsj1965.65.3_373

Qian, C., and Zhou, T. (2014). Multidecadal Variability of North China Aridity and its Relationship to PDO during 1900-2010. J. Clim. 27 (3), 1210-1222. doi:10. 1175/JCLI-D-13-00235.1

Rayner, N. A., Parker, D. E., Horton, E. B., Folland, C. K., Alexander, L. V., Rowell, D. P., et al. (2003). Global Analyses of Sea Surface Temperature, Sea Ice, and Night marine Air Temperature since the Late Nineteenth century. J. Geophys. Res. 108 (D14), 4407. doi:10.1029/2002JD002670

Simmons, A., Uppala, S., Dee, D., and Kobayashi, S. (2007). ERA Interim: New ECMWF Reanalysis Products from 1989 Onwards. ECMWF Newsl. 110, 25-35. Available at: https://www.researchgate.net/publication/ 255267047_ERAInterim_New_ECMWF_reanalysis_products_from 1989_onwards

Wang, C., Yang, K., Li, Y., Wu, D., and Bo, Y. (2017). Impacts of Spatiotemporal Anomalies of Tibetan Plateau Snow Cover on Summer Precipitation in Eastern China. J. Clim. 30 (3), 885-903. doi:10.1175/JCLI-D-16-0041.1

Wang, L., Wang, C., and Guo, D. (2018). Evolution Mechanism of SynopticScale EAP Teleconnection Pattern and its Relationship to Summer Precipitation in China. Atmos. Res. 214, 150-162. doi:10.1016/j. atmosres.2018.07.023

Wang, S., and Zuo, H. (2016). Effect of the East Asian Westerly Jet's Intensity on Summer Rainfall in the Yangtze River Valley and its Mechanism. J. Clim. 29 (7), 2395-2406. doi:10.1175/JCLI-D-15-0259.1

Wang, Z., Duan, A., and Wu, G. (2014). Time-lagged Impact of spring Sensible Heat over the Tibetan Plateau on the Summer Rainfall Anomaly in East China: Case Studies Using the WRF Model. Clim. Dyn. 42, 2885-2898. doi:10.1007/ s00382-013-1800-2

Wu, G., Liu, Y., Zhang, Q., Duan, A., Wang, T., Wan, R., et al. (2007). The Influence of Mechanical and thermal Forcing by the Tibetan Plateau on Asian Climate. J. Hydrometeor 8, 770-789. doi:10.1175/JHM609.1

Xu, K., Huang, Q.-L., Tam, C.-Y., Wang, W., Chen, S., and Zhu, C. (2019). Roles of Tropical SST Patterns during Two Types of ENSO in Modulating Wintertime Rainfall over Southern China. Clim. Dyn. 52 (1/2), 523-538. doi:10.1007/ s00382-018-4170-y

Xuan, S., Zhang, Q., Sun, S., and Shi, C. (2018). Contrast in the East Asian Subtropical westerly Jet and its Association with Precipitation in China between Early Summer and Midsummer. Met. Apps 25 (1), 119-127. doi:10.1002/met. 1675

Yanai, M., Li, C., and Song, Z. (1992). Seasonal Heating of the Tibetan Plateau and its Effects on the Evolution of the Asian Summer Monsoon. J. Meteorol. Soc. Jpn. 70 (1), 319-351. doi:10.2151/jmsj1965.70.1B_319
Yang, S., and Xu, L. (1994). Linkage between Eurasian winter Snow Cover and Regional Chinese Summer Rainfall. Int. J. Climatol. 14 (7), 739-750. doi:10. 1002/joc.3370140704

Yu, R., Wang, B., and Zhou, T. (2004). Tropospheric Cooling and Summer Monsoon Weakening Trend over East Asia. Geophys. Res. Lett. 31, L22212. doi:10.1029/2004GL021270

Zhang, L., Wu, P., Zhou, T., and Xiao, C. (2018). ENSO Transition from La Niña to El Niño Drives Prolonged Spring-Summer Drought over North China. J. Clim. 31 (9), 3509-3523. doi:10.1175/JCLI-D-17-0440.1

Zhang, R., Sumi, A., and Kimoto, M. (1999). A Diagnostic Study of the Impact of El Niño on the Precipitation in China. Adv. Atmos. Sci. 16, 229-241. doi:10.1007/ BF02973084

Zhang, Y., Li, Z., and Liu, B. (2015). Interannual Variability of Surface Sensible Heating over the Tibetan Plateau in Boreal spring and its Influence on the Onset Time of the Indian Summer Monsoon. Chin. J. Atmos. Sci. (In Chinese) 39 (6), 1059-1072. doi:10.3878/j.issn.1006-9895.1410.14226

Zhao, P., and Chen, L. (2001). Climatic Features of Atmospheric Heat Source/sink over the Qinghai-Xizang Plateau in 35 Years and its Relation to Rainfall in China. Sci. China Ser. D-earth Sci. 44 (9), 858-864. doi:10.1007/BF02907098

Zhao, Y., Duan, A., and Wu, G. (2018). Interannual Variability of Late-spring Circulation and Diabatic Heating over the Tibetan Plateau Associated with Indian Ocean Forcing. Adv. Atmos. Sci. 35, 927-941. doi:10.1007/s00376-0187217-4

Zhao, Y., Duan, A., Wu, G., and Sun, R. (2019). Response of the Indian Ocean to the Tibetan Plateau thermal Forcing in Late spring. J. Clim. 32 (20), 6917-6938. doi:10.1175/JCLI-D-18-0880.1

Zhou, X., Zhao, P., Chen, J., Chen, L., and Li, W. (2009). Impacts of Thermodynamic Processes over the Tibetan Plateau on the Northern Hemispheric Climate. Sci. China Ser. D-earth Sci. 52, 1679-1693. doi:10. 1007/s11430-009-0194-9

Zhu, Y., Wang, H., Ma, J., Wang, T., and Sun, J. (2015). Contribution of the Phase Transition of Pacific Decadal Oscillation to the Late 1990s' Shift in East China Summer Rainfall. J. Geophys. Res. Atmos. 120 (17), 8817-8827. doi:10.1002/ 2015JD023545

Conflict of Interest: The authors declare that the research was conducted in the absence of any commercial or financial relationships that could be construed as a potential conflict of interest.

Copyright (c) 2021 Chen, Nan, Liu, Zhou, Shi, Ao and Li. This is an open-access article distributed under the terms of the Creative Commons Attribution License (CC $B Y)$. The use, distribution or reproduction in other forums is permitted, provided the original author(s) and the copyright owner(s) are credited and that the original publication in this journal is cited, in accordance with accepted academic practice. No use, distribution or reproduction is permitted which does not comply with these terms. 